\title{
Persistent Monetary Non-neutrality in an Estimated Model with Menu Costs and Partially Costly Information*
}

\author{
Marco Bonomo \\ Carlos Carvalho \\ René Garcia \\ Vivian Malta \\ Insper \\ PUC-Rio \\ EDHEC Business School \\ BTG Pactual
}

February 2015

\begin{abstract}
We propose a price-setting model which helps to reconcile micro evidence of relatively frequent price adjustments with macroeconomic persistent effects of aggregate shocks. In our model, both price adjustments and the gathering of some types of information are costly, requiring the payment of a lump-sum cost. Additional relevant information flows continuously, and can be factored into pricing decisions costlessly. We estimate three versions of the model by a Simulated Method of Moments, including a special case in which all information is costly. When idiosyncratic information is free and aggregate information is costly, our estimated model is able to match individual price-setting statistics for the U.S. and, at the same time, produce persistent monetary non-neutrality.
\end{abstract}

JEL classification codes: E00, E31

Keywords: menu costs, information costs, infrequent information, partial information, inattentiveness, optimal price setting, state-dependent pricing, time-dependent pricing.

${ }^{*}$ We thank seminar participants at Bank of England, REAP session at SBE 2014, INSPER, LAMES-LACEA 2014, Cambridge, Oxford, UCL, Columbia, Bank of Canada, LuBraMacro 2013 (Portuguese-Brazilian Macro Workshop), Columbia, FRB of Minneapolis and USP for comments and suggestions. Emails: bonomo@insper.edu.br, cvianac@econ.puc-rio.br, rene.garcia@edhec.edu, vivan.malta@btgpactual.com. 


\section{Introduction}

The recent availability of vast amounts of micro price data has generated renewed interest in price setting among macroeconomists, especially since the seminal work of Bils and Klenow (2004), which showed that price-adjustments are more frequent than previously thought. This has lead to noteworthy developments in this field - in particular in terms of microfounded models with explicit price-setting frictions. Many papers have expanded the frontier of so-called menu-cost models. ${ }^{1}$ In addition, recent work has analyzed the implications of explicit informational frictions for pricesetting behavior. ${ }^{2}$ Menu costs models fit microdata reasonably well, but, as Golosov and Lucas (2007) point out, are unable to generate meaningful macroeconomic effects. On the other hand, information costs generate more realistic macroeconomic effects, but not the type of price stickness observed in the data. ${ }^{3}$

In this paper we propose a price-setting model that helps to reconcile micro evidence of relatively frequent price adjustments with macroeconomic persistent effects of aggregate shocks. In our pricesetting model both adjustments and the gathering of some types of information are costly, requiring the payment of lump-sum costs. ${ }^{4}$ Additionally, another relevant part of the information flows continuously and can be factored into pricing decisions somewhat costlessly. ${ }^{5}$ When idiosyncratic information is free and aggregate information is costly, our model is able to match individual pricesetting statistics and, at the same time, produce persistent macroeconomic effects. ${ }^{6}$ It turns out that this is the version of the model favored by a comparison of untargeted data moments with those produced by the different models that we take to the data.

The optimal price-setting model we propose is not trivial to solve. In order to do that, we develop a tractable unified framework for solving optimal time- and state-dependent price-setting problems. Our framework may be used to study several models with adjustment costs and infrequent information, including most price-setting problems analyzed previously in the literature. ${ }^{7}$ Thus, our contribution is also methodological.

\footnotetext{
${ }^{1}$ Some examples are Golosov and Lucas (2007), Gertler and Leahy (2008), Midrigan (2011), and Nakamura and Steinsson (2010).

${ }^{2}$ For instance, Reis (2006), Woodford (2009), Maćkowiak and Wiederholt (2009).

${ }^{3}$ For example, if there is a known drift in the frictionless optimal price, the optimal pricing policy when there is a lump-sum information cost implies that the price should continuously change according to this drift.

${ }^{4}$ The literature on price setting with information frictions usually assumes only one type of information (e.g.Caballero 1989, Reis 2006, Moscarini 2004, Bonomo and Carvalho 2004,2010, Woodford 2009, Gorodnichenko 2008, Knotek 2009, Klenow and Willis 2007, and Alvarez, Lippi, and Paciello 2011).

${ }^{5}$ Gorodnichenko (2008), Knotek (2009) and Klenow and Willis (2007) propose menu-cost models in which firms continuously incorporate partial information into pricing decisions.

${ }^{6}$ Readers familiar with Mackowiak and Wiederholt (2009) will recognize a flavor of their main result here. However, their model features only information frictions, and prices change constinuously.

${ }^{7}$ In Bonomo, Carvalho, Garcia (2011) we use this framework to solve several models with costly adjustment and/or infrequent information.
} 
The key to making our approach tractable is our choice of state variables. We rely on a commonly used second-order approximation to the profit loss due to price-setting frictions, which implies that these losses are proportional to the square of the discrepancy between the firm's (log) price and its frictionless optimal level (henceforth the price discrepancy). Because of the intertemporal nature of the problem, the price setter must forecast the path of these squared discrepancies. Given the stochastic processes used to model the frictionless optimal price, these forecasts turn out to be a very simple function of two conveniently chosen state variables: the conditional expectation of the price discrepancy and the time elapsed since the last date when information was fully factored into the pricing decision (henceforth information dates). This choice of state variables allows us to cast the pricing problem as a two-dimensional optimal stopping problem. We rewrite the Bellman equation that characterizes the firm's value function in the inaction region as a partial differential equation, and obtain the solution by imposing the boundary conditions dictated by the nature of the problem and applying a finite-difference method.

In our partial information model, a firm always has the option to incur the lump-sum adjustment cost $(K)$ and make a price adjustment based on its current information about the underlying frictionless optimal price. It can also incur the lump-sum information cost $F$ to become fully informed. Under these circumstances, the optimal policy is characterized by an inaction region for price adjustment and information gathering/processing, which is defined by the intersection between an adjustment inaction region and an information inaction region. The borders inherited from the adjustment inaction region trigger uninformed adjustments, while the border inherited from the information inaction region triggers information gathering/processing. The adjustment inaction region varies with the time elapsed since the last information date. The reason is that the option value of waiting for new information tends to increase with time, due to the accumulation of underlying (unobserved) innovations. To the best of our knowledge, this dependence of the adjustment inaction region on the age of the firm's information set is a feature of optimal pricing policies that had not emerged in previous work.

We also analyze a particular case of the model where there is no freely available partial information. Then the model becomes one in which all the information is costly, as in Alvarez, Lippi, and Paciello (2011). The main difference is that our approach also encompasses cases in which uninformed adjustments are optimal. ${ }^{8}$

\footnotetext{
${ }^{8}$ See also Gorodnichenko (2008), Abel, Eberly, and Panageas (2010), Alvarez, Guiso, and Lippi (2010). In Gorodnichenko's (2008) model, firms always have some (imperfect) information about the frictionless optimal price. Abel, Eberly and Panageas (2010) show that their asymptotic result of convergence to a purely time-dependent portfolio management policy survives if one allows for what they refer to as "automatic transfers" between the agent's investment portfolio and the transactions account. However, they do not investigate the optimality of automatic transfer plans. Alvarez, Lippi and Paciello (2010, section 7.3) and Alvarez, Guiso and Lippi (2010, Appendix AA-3) discuss the case of adjustment without information. They provide sufficient conditions under which such uninformed
} 
We use price-setting statistics computed from price micro data from the U.S. Bureau of Labor Statistics to estimate the main parameters of the model by a Simulated Method of Moments (SMM). Simulation-based methods are necessary, since the relationship between the model parameters and observable statistics is highly non-linear and complex. We estimate the partial information model under two alternative hypotheses for the costly and free components. In one version, the price-setter can costlessly incorporate all the information about aggregate shocks into her pricing decision, while observing/processing idiosyncratic shocks is costly. The other version of the model reverses these assumptions. Finally, we also estimate the model in which all information is costly.

All three models fit the targeted moments reasonably well, but they perform distinctly in fitting the distribution of duration of pricing spells - an untargeted "moment". The partial information model with costly aggregate information is the only one capable of generating a distribution that resembles the empirical distribution reported in Klenow and Kryvtsov (2009). A more important difference between the estimated models is the frequency of information collection generated by the implied pricing rules. Both the partial information model with costly idiosyncratic information and the model with costly only information lead to high frequency of information collection - higher than the frequency of price adjustments. In contrast, the frequency of information collection in the partial information model with costly aggregate information is about three times less often than the frequency of price adjustments.

When we compare the three models in terms of the effects of a monetary shock, the frequency of aggregate information collection turns out to be key for the persistence of non-neutrality, and so monetary shocks are substantially more persistent in the partial information model with costly aggregate information.

The rest of the paper is planed as follows. In Section 2.2 we present our general framework for solving price-setting problems with adjustment and/or information frictions. We then apply the framework to solve our optimal pricing rule problem under partial information. The optimal rule when all information is costly is also solved as a particular case of our model. Section 3 presents the data, the estimation method and the results. The estimated pricing rules are numerically aggregated in order to analyze the effect of a money shock in Section 4 . The last section concludes.

adjustments are not optimal. For the price-setting problem, Alvarez, Lippi and Paciello (2010) show that this is the case for a sufficiently small rate of inflation. For the problem of asset management with consumption of durables, Alvarez, Guiso and Lippi (2010) show that this is the case when there is no uncertainty in asset returns. These two papers then focus on parameterizations that satisfy those sufficient conditions, and otherwise prevent agents from making uninformed adjustments by imposing the restriction that adjustment requires observation. For a more extensive discussion of the differences between our work and these papers, see Bonomo, Carvalho, and Garcia (2011). 


\section{A model with menu costs and partially costly information}

\subsection{Informal description}

We develop a model of price setting with costly price adjustments and partially costly information. In the absence of these frictions, each firm would set its price equal to its instantaneous profitmaximizing price - the so-called frictionless optimal price. In Appendix A, we present a simple general equilibrium model that yields an expression for the (logarithm of the) frictionless optimal price for a firm as the sum of two components - a common (nominal aggregate demand) and an idiosyncratic (productivity) component. Information about one of these components is continuously and freely available, and can be factored into price-setting decisions somewhat costlessly. Gathering and processing information about the other component entails a lump-sum information cost $(F)$. At this point we remain agnostic about which component is costly. Hence, we refer to them as the "free" and "costly" components. Later, when we estimate the model, we entertain the two alternatives - namely, costly aggregate information and free idiosyncratic information, and viceversa - and let the data inform us which component is better modeled as costly. The loss in profits per unit of time from charging a sub-optimal price is increasing in its distance from the frictionless optimal price. Price changes entail a lump-sum menu cost $(K)$.

Intuitively, because of the lump-sum nature of the information cost, a firm will choose to gather and process information about the costly component of its frictionless optimal price only at certain dates, which we refer to as information dates. In between information dates, decisions about whether to incur the menu cost to change its price will have to be conditioned on the firm's best estimate of its frictionless optimal price, given its (partial) information. These two possible choices - changing prices or gathering information - imply an optimal inaction region, which we describe heuristically before spelling out the model in detail and explaining how we solve this pricing problem.

Let $z_{t}$ denote the difference between the firm's price and the best estimate of its frictionless optimal price, given the firm's information. ${ }^{9}$ We refer to $z_{t}$ as the expected price discrepancy. Upon incurring the menu cost $K$, the firm can choose a new price, and will do so in order to set the expected price discrepancy $z_{t}$ to an optimal level, which we denote by $c_{t}$. For a given information set, adjustment is only worthwhile if the expected price discrepancy is "large enough" to justify incurring the menu cost. This implies that at each point in time there are bounds $l_{t}$ and $u_{t}$ on the expected price discrepancy such that the firm will increase its price whenever $z_{t}$ is less than $l_{t}$, and decrease its price whenever $z_{t}$ exceeds $u_{t}$. The assumptions about the process for the frictionless

\footnotetext{
${ }^{9}$ Under full information, this variable corresponds to the standard state variable used to solve menu-cost models (e.g., Dixit 1991).
} 
optimal price that we specify subsequently imply that the policy functions $\left\{l_{t}, c_{t}, u_{t}\right\}$ do not depend on calendar time per se, but only on the time elapsed since the last information date, denoted $\tau$ (i.e., the last time the firm paid the information $\operatorname{cost} F$ to gather full information about its frictionless optimal price). We thus write $\{l(\tau), c(\tau), u(\tau)\}$, and refer to $\{l(\tau), u(\tau)\}$ as the bounds of the adjustment inaction region.

Turning to the information decision, upon incurring the information cost $F$ the firm learns the history of innovations to the costly component of its frictionless optimal price. This amounts to a shock to the best estimate of the price discrepancy that the firm held just prior to gathering information. At any given time $t$, gathering information is only worthwhile if the cost of not observing the innovations that have occurred since the last information date exceeds the information cost $F$. As long as the uncertainty associated with the best guess of the frictionless optimal price increases with the time elapsed since the last information date, the cost of not observing the underlying innovations will increase over time. Hence, for each expected price discrepancy $z$, the optimal policy specifies a time elapsed since the last information date $\left(\tau^{*}(z)\right)$ that triggers information gathering. We refer to $\tau^{*}(z)$ as the boundary of the information inaction region.

Figure 1 shows the optimal policy for illustrative parameter values. The solid (red) lines depict the adjustment policy $\{l(\tau), c(\tau), u(\tau)\}$, with the outer lines delimiting the adjustment inaction region. The dashed (blue) line sets the limit of the information inaction region. The (solid, red) borders of the adjustment inaction region trigger partially informed adjustments, while the border of the information inaction region triggers information gathering/processing. In practice, because firms have the options to adjust and to become informed, they will always find themselves within the boundaries of both inaction regions. ${ }^{10}$ Hence, their intersection determines the relevant statespace. We discuss other features of the optimal policy subsequently, in Section X. We now turn to the specifics of the model and the solution method.

\subsection{The model}

We first solve the optimal price-setting problem of a single firm, and later estimate a model of an economy populated by a large number of such firms. Hence, to avoid cluttering notation, we omit individual firms' subscripts and denote a firm's frictionless optimal price by $p_{t}^{*}$. We assume $p_{t}^{*}$ evolves according to:

$$
d p_{t}^{*}=\mu d t-\sigma_{f} d W_{f, t}-\sigma_{c} d W_{c, t}
$$

\footnotetext{
${ }^{10}$ This is true as long as the underlying process for the frictionless optimal price is continuous (which we will assume). The only exceptions are information dates, on which the firm may learn that its price discrepancy is outside the adjustment inaction region for $\tau=0$. But in those case the firm will choose to incur the menu cost and adjust immediately to $c(0)$. Hence, for practical purposes the relevant state space is the intersection between the adjustment and information inaction regions.
} 


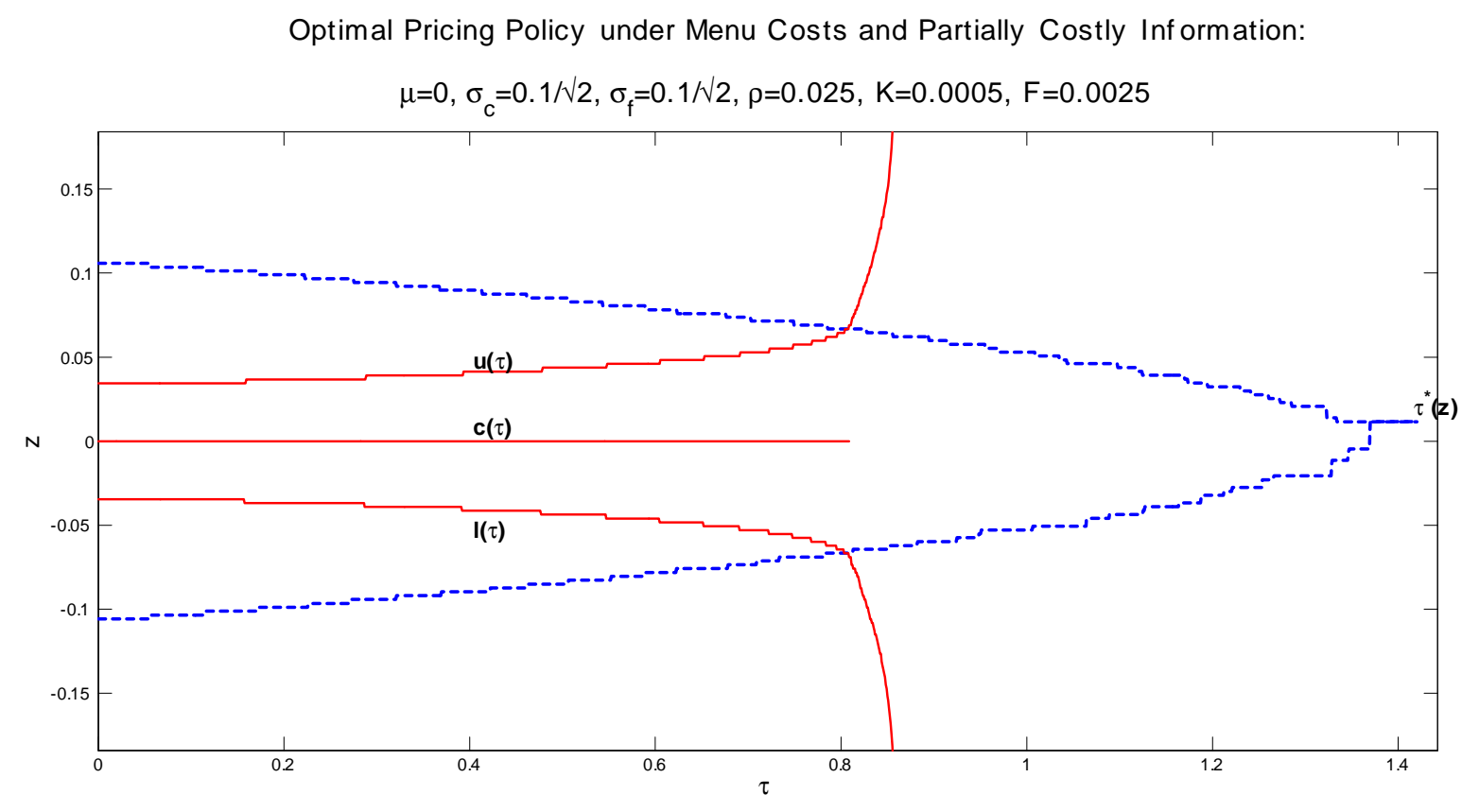

Figure 1: Optimal pricing policy menu costs and partially costly information

where $W_{f, t}$ and $W_{c, t}$ are independent standard Wiener processes. Information about $W_{f, t}$ is continuously and freely available, and costless to process. In contrast, gathering and processing information about $W_{c, t}$ is costly. Any discrepancy between a firm's actual price $p_{t}$, and its frictionless optimal price $p_{t}^{*}$ entails an instantaneous flow "cost" in the form of foregone profits. As we show in Appendix B, these discrepancy costs can be taken as being approximately equal to the square of the price discrepancy: $\left(p_{t}-p_{t}^{*}\right)^{2}$. The objective of firms is to minimize the present discounted value of expected total costs, which comprise flow discrepancy costs and lump-sum adjustment and information costs. ${ }^{11}$

Under partial information about $p_{t}^{*}$, in order to evaluate the expected flow cost due to price discrepancies the firm must form a probabilistic assessment of $p_{t}^{*}$ given its information. We can decompose the expected discrepancy cost at time $t$ as:

$$
E_{t}\left(p_{t}-p_{t}^{*}\right)^{2}=\left(p_{t}-E_{t} p_{t}^{*}\right)^{2}+\operatorname{Var}_{t}\left(p_{t}^{*}\right)
$$

where $\operatorname{Var}_{t}$ denotes the conditional variance given time $t$ information. Because the firm has continuous access to partial information about $p_{t}^{*}$, the conditional variance $\operatorname{Var}_{t}\left(p_{t}^{*}\right)$ refers to the component of the frictionless optimal price that is only observed at a cost - that is, to the $\sigma_{c} d W_{c, t}$ component in equation (1).

\footnotetext{
${ }^{11}$ Appendix $\mathrm{C}$ formalizes the firm's dynamic optimization problem.
} 
The first term in the right-hand side of (2) represents the flow cost of deviating from the expected level of the frictionless optimal price, and the second term represents the expected flow cost from not continuously entertaining full information about $p_{t}^{*}$. In the absence of adjustment costs, $p_{t}$ would be set equal to $E_{t} p_{t}^{*}$, reducing the first part of the expected discrepancy cost to zero. Otherwise the firm must optimally solve the trade-off between letting $p_{t}$ drift away from $E_{t} p_{t}^{*}$, and paying the cost to adjust based on partial information. As for the second term in (2), it is zero when information can be fully and continuously incorporated into the pricing decision at no cost, as in standard menu-cost models. If information gathering and processing is costly, the firm can reduce that second term at the expense of incurring the information cost.

For any given time $t$ for which the last information date was at time $t_{0}<t$, recall that $\tau \equiv t-t_{0}$ denotes the time elapsed since the last information date. Also, recall that $z_{t} \equiv p_{t}-E_{t} p_{t}^{*}$ denotes the expected price discrepancy at time $t$. With these definitions we can rewrite the firm's expected discrepancy cost (2) as a function of $\tau$ and $z$ :

$$
E_{t}\left(p_{t}-p_{t}^{*}\right)^{2}=z_{t}^{2}+\sigma_{c}^{2} \tau
$$

As a consequence, we can write the value function at a time $t$ - the optimized value of the firm's dynamic cost-minimization problem described above, and formalized in Appendix $\mathrm{C}$ - in terms of the two state variables $z_{t}$ and $\tau$. In the inaction region (i.e., absent any price change and/or costly information gathering), the value function, $V\left(z_{t}, \tau\right)$, obeys the following Bellman equation:

$$
V\left(z_{t}, \tau\right)=\left(z_{t}^{2}+\sigma_{c}^{2} \tau\right) d t+e^{-\rho d t} E_{t} V\left(z_{t+d t}, \tau+d t\right)
$$

Between information dates and in the absence of price adjustments (i.e., in the inaction region), $z_{t}$ changes continuously because of both the drift $\mu$ and the free component of the frictionless optimal price, $W_{f, t}$ :

$$
d z_{t}=-\mu d t+\sigma_{f} d W_{f, t}
$$

Taking into account the process for the expected price discrepancy $z$ (equation 5) and applying Ito's lemma, the evolution of the value function in the inaction region can be described by the following partial differential equation:

$$
\frac{1}{2} \sigma_{f}^{2} V_{z z}(z, \tau)-V_{z}(z, \tau) \mu+V_{\tau}(z, \tau)-\rho V(z, \tau)+z^{2}+\sigma_{c}^{2} \tau=0
$$

Solving for the value function requires the specification of boundary conditions, which are dictated by the price adjustment and information gathering/processing decisions. We analyze each of these decisions in turn. 


\subsubsection{The adjustment decision}

Because adjustment costs are lump-sum, price adjustments at any point in time minimize the value function for that time elapsed since the last information date. Hence the target point $c(\tau)$ when the time elapsed is $\tau$ satisfies:

$$
c(\tau)=\arg \min _{z} V(z, \tau), \forall \tau
$$

Since firms always have the option to incur the adjustment cost $K$ and reset the expected discrepancy to $c(\tau)$, optimality implies that the value function must always satisfy:

$$
V(z, \tau) \leq K+V(c(\tau), \tau), \forall(z, \tau)
$$

The bounds that define the adjustment inaction region, $l(\tau), u(\tau)$, are functions of the time elapsed since the last information date that imply indifference between adjusting and not adjusting. Hence they satisfy the value-matching conditions that obtain when (8) holds with equality:

$$
\begin{gathered}
V(l(\tau), \tau)=K+V(c(\tau), \tau), \\
V(u(\tau), \tau)=K+V(c(\tau), \tau) .
\end{gathered}
$$

\subsubsection{The information decision}

Firms always have the option to incur the information cost $F$ to gather and process information about the costly $W_{c, t}$ component. Upon doing so, they learn the realization of $W_{c, t}$ - or, equivalently, their frictionless optimal price $p_{t}^{*}$ - and the time elapsed since the last information date, $\tau$, is reset to zero. The decision of whether or not to get informed at any given point in time involves comparing the current value function with a lottery that will yield a new value function after the realization of $W_{c, t}$ is learned. Taking the lottery requires paying the information cost $F$. Optimality requires that the current value function does not exceed the sum of the information cost and the expected value of the lottery, that is:

$$
V(z, \tau) \leq F+E\left[V\left(z+\sigma_{c} \sqrt{\tau} \varepsilon, 0\right)\right], \forall(z, \tau)
$$

where $\varepsilon$ is a standard normal random variable.

Points in the state space in which the firm is indifferent between getting informed and continuing with outdated information, for which (10) holds with equality, define the information boundary $\left(z, \tau^{*}(z)\right)$. Thus, on information dates the expected price discrepancy receives a shock with distribution $N\left(0, \sigma_{c}^{2} \tau^{*}(z)\right)$, and $\tau$ is reset to zero, yielding the following "informational matching 
condition":

$$
V\left(z, \tau^{*}(z)\right)=F+E\left[V\left(z+\sigma_{c} \sqrt{\tau^{*}(z)} \varepsilon, 0\right)\right]
$$

\subsection{The optimal pricing rule}

We solve this pricing problem using a finite-difference method, which we describe in Appendix ZZZ [No apendice, enfatizar a forma de impor otimalidade no grid]. Figure 2 illustrates the optimal pricing rule under adjustment and information costs, and partial information. When we jointly take into account the adjustment and information inaction regions, we do not need to consider information decisions at $(z, \tau)$ points that are outside the adjustment inaction region, since those points will never be reached. Likewise, there is no need to contemplate $(z, \tau)$ points that are outside the information inaction region. Thus, the resulting inaction region (depicted in Figure 2), in which no adjustment or information gathering occurs, is the intersection between the adjusment and information inaction regions.

Under the optimal rule, the firm uses $W_{f, t}$-information between information dates and adjusts the expected price discrepancy to $c(\tau)$ whenever it hits the $l(\tau)$ or $u(\tau)$ boundaries of the inaction region (outer solid (red) lines, inherited from the adjustment inaction region). The inner solid (red) line, $c(\tau)$, gives the expected discrepancy to which the firm reverts whenever it chooses to adjust. The dashed (blue) line $\tau^{*}(z)$ is the boundary of the inaction region, inherited from the information inaction region, which triggers information gathering.

Notice that the sizes of price adjustments implied by the optimal rule are not constant, as they would be under full information. ${ }^{12}$ Partially informed upward adjustments have size $c(\tau)-l(\tau)$, while partially informed price decreases have size $u(\tau)-c(\tau)$. Those adjustment sizes depend on the time elapsed since the last information date. In the example presented in Figure 2, in which there is a positive drift in the frictionless optimal price process, the partially informed upward adjustment size clearly increases with $\tau$. Fully informed adjustments are potentially much more variable in size, with lower bound $c(0)-l(0)$ for price increases and $u(0)-c(0)$ for price decreases.

In the sample path realization for the expected price discrepancy $\left(z_{t}\right)$ that we depict in Figure 2 (solid (black) line), there are two partially-informed adjustments before the firm decides to incur the cost to entertain information about $W_{c, t}$. At that point the time-elapsed variable $\tau$ is reset to zero, and the firm learns the cumulative innovation $W_{c, t}-W_{c, t-\tau^{*}(z)} \sim N\left(0, \sigma_{c}^{2} \tau^{*}(z)\right)$. Then, the firm decides whether or not to incur the menu cost and change its price, depending on whether the

\footnotetext{
${ }^{12}$ In a pure menu-cost version of the model, our assumed process for the frictionless optimal price would generate constant adjustment sizes for both price increases and decreases. Of course adding mean reversion in the frictionless optimal price process, as in Golosov and Lucas (2008), or economics of scope in menu costs, as in Midrigan (2011), would introduce some size variability.
} 
price discrepancy is inside or outside the inaction region defined by $(l(0), u(0))$.

For small $\tau$, the limits of the inaction region are dictated by the boundaries of the adjustment inaction region, whereas for large $\tau$ they are defined by the boundary of the information inaction region. When information about $W_{c, t}$ is not yet too stale, partial information about $p_{t}^{*}$ might lead to a large enough expected price discrepancy, inducing the firm to make a partially-informed price adjustment. After some point (corresponding to $\tau \approx 1.2$ in Figure 2), making partially-informed adjustments is no longer optimal. The reason is that by that time the firm's information set has "depreciated" enough (due to the accumulation of unobserved innovations to $W_{c, t}$ ). Thus, a given expected discrepancy that might have triggered a partially-informed adjustment early on, will now trigger information gathering instead.

An interesting implication of optimal pricing behavior under adjustment and information costs, which can be glimpsed from the previous description, is that it is never optimal to make a partiallyinformed adjustment just prior to an information date. Rather than incurring the menu cost to make such an adjustment and then immediately incurring the information cost, it is always better to reverse the order of these actions and keep the option to adjust, to be exercized or not depending on the new information. ${ }^{13}$

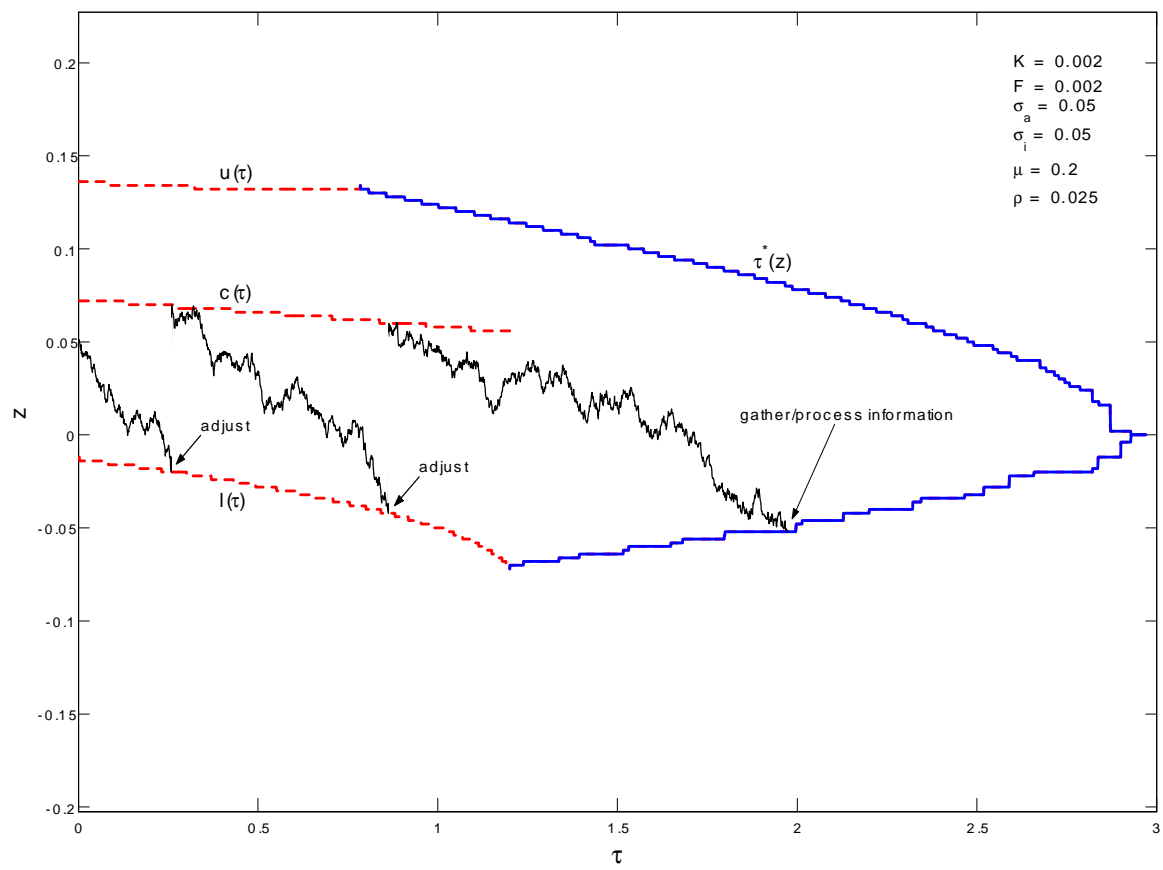

\footnotetext{
${ }^{13}$ In Bonomo, Carvalho, and Garcia (2011) we show that the principle that it is never optimal to make an adjustment just prior to the arrival of relevant information is rather general. In particular, we illustrate this point in a setting in which information dates are exogenous and known to firms. In that case, the width of the adjustment inaction region increases to infinity just before an information date.
} 
Figure 2: Optimal pricing policy with partial information, and adjustment and information costs

\subsection{A particular case with costly information only}

In this section, we use our framework to tackle a particular case of the problem in section 2 , in which all information is costly. This case is analyzed in Alvarez, Lippi, and Paciello (2010). They show that, when inflation is low enough, it is never optimal for firms to adjust prices without information. They solve the model under this assumption. Our solution method allows us to solve for the optimal pricing problem in the more general case in which uninformed adjustments might be optimal. ${ }^{14}$ This is the case if inflation is high enough or, for a given trend inflation $(\mu \neq 0)$, if adjustment costs are small enough relative to information costs.

We solve this problem by fixing $\sigma_{f}=0$ and relabeling $\sigma=\sigma_{c}$ in the setting of Section 2. Thus, the differential equation which characterizes the evolution of the value function inside the inaction region becames:

$$
-\mu V_{z}(z, \tau)+V_{\tau}(z, \tau)-\rho V(z, \tau)+z^{2}+\sigma^{2} \tau=0
$$

The conditions related to the adjustment decision (7,8 and 9) and information decision $(10,11)$ remain the same.

We also solve this problem numerically using a finite-difference method. ${ }^{15}$ Figure 3 illustrates the optimal pricing rule under adjustment and information gathering/processing costs. The solid (red) lines $l(\tau), u(\tau)$ are the boundaries of the inaction region that trigger uninformed adjustments, while the dashed (blue) line $\tau^{*}(z)$ is the boundary that triggers information gathering/processing. We illustrate the optimal pricing behavior with a sample path. Initially, $z_{t}$ is close to zero. Due to the high enough drift $\mu$, the expected discrepancy hits the lower boundary $l(\tau)$, leading to an uninformed adjustment to $c(\tau)$. After that, the expected discrepancy drifts down until it touches the information boundary $\tau^{*}(z)$ at a point where $z \approx-0.04$ and $\tau \approx 0.73$. At that point the firm incorporates information into the pricing decision, as the expected discrepancy receives a shock with distribution $N\left(0, \sigma^{2} \times 0.73\right)$. The time-elapsed variable $\tau$ is reset to zero, and the firm decides whether or not to pay the menu cost and change its price, depending on whether the justlearned price discrepancy is inside or outside the inaction region on information dates, defined by $(l(0), u(0))$. Once again, notice that it is never optimal to make an uninformed price adjustment just prior to an information date.

\footnotetext{
${ }^{14}$ For a more detailed discussion of the differences between our models see Bonomo, Carvalho, and Garcia (2011).

${ }^{15}$ See Bonomo, Carvalho, and Garcia (2011) for details.
} 


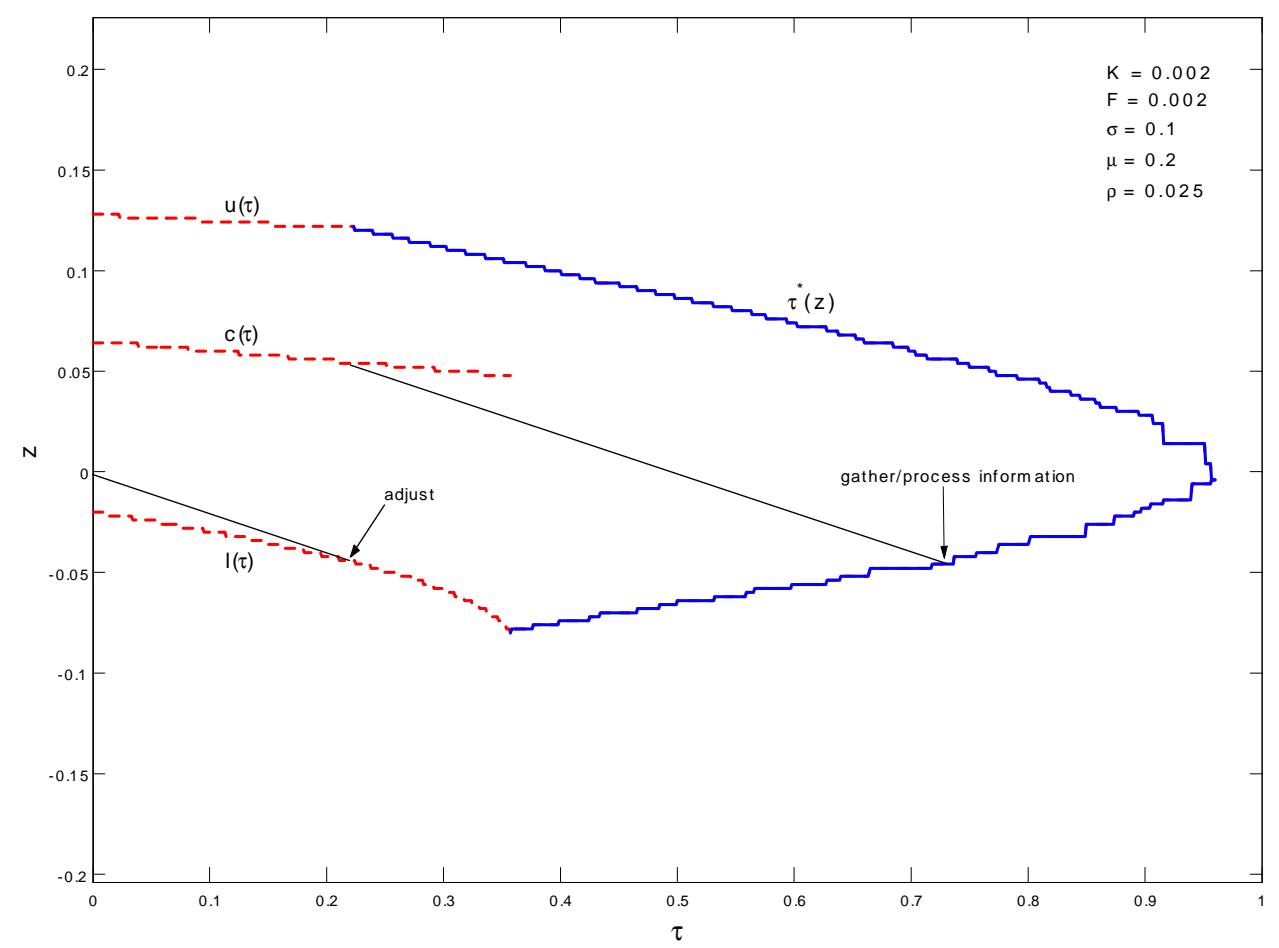

Figure 2: Optimal pricing policy in the model with costly information only

\section{Estimating the model}

We use price-setting statistics computed from price micro data from the U.S. Bureau of Labor Statistics to estimate the main parameters of the model by a Simulated Method of Moments (SMM). Simulation-based methods are necessary, since the relationship between the model parameters and observable statistics is highly non-linear and complex. We estimate the partial information model under two alternative hypotheses for the costly and free components. In one version, the price-setter can costlessly incorporate all the information about aggregate shocks into her pricing decision, while observing/processing idiosyncratic shocks is costly. The other version of the model reverts these assumptions. Finally, we also estimate the model in which all information is costly.

\subsection{Estimation method}

SMM estimates result from the minimization of the distance between data moments and moments obtained through simulation of the model. This requires that, for each set of parameter values, we 
solve for the optimal pricing rule, and then simulate an economy with a large number of firms. ${ }^{16}$

Let $\Phi \in \mathbb{R}^{p}$ be a vector of model parameters to be estimated, $\Psi_{\text {data }} \in \mathbb{R}^{q}(q \geq p)$ a vector of data moments and $\Psi_{\text {sim }}(\Phi) \in \mathbb{R}^{q}$ a vector of the corresponding moments calculated from the model's simulated data. The estimator $\hat{\Phi}$ is obtained by solving the following minimization problem:

$$
\min _{\Phi}\left(\Psi_{d a t a}-\Psi_{s i m}(\Phi)\right)^{\prime} W\left(\Psi_{d a t a}-\Psi_{s i m}(\Phi)\right)
$$

where $W$ is the optimal $q \times q$ weighting matrix, given by the inverse of the variance-covariance matrix of the sample moments $\Psi_{\text {data }}$ adjusted for simulation error. ${ }^{17}$

In accordance with the model detailed in Appendix A, all firms' frictionless optimal prices are subject to nominal aggregate shocks, and idiosyncratic shocks that are independent across firms. Estimating the version of the partial-information model in which idiosyncractic shocks are free and aggregate shocks are costly amounts to setting $\sigma_{c}=\sigma_{a}$ and $\sigma_{f}=\sigma_{i}$. The other version of the partial-information model obtains when $\sigma_{c}=\sigma_{i}$ and $\sigma_{f}=\sigma_{a}$. In the model in which all information

is costly, $\sigma_{f}=0$ and $\sigma_{c}=\sqrt{\sigma_{i}^{2}+\sigma_{a}^{2}}$. Note, however, that aggregate and idiosyncratic shocks still have potentially different effects on price-setting statistics in this model. In particular, idiosyncratic shocks do not generate time variation in aggregate price-setting statistics. ${ }^{18}$

We calibrate the average inflation rate $(\mu)$ to match the sample average over the period during which the micro data used to computed the empirical price-setting statistics were sampled. To reduce the number of parameters and save on computational time, we also set $\rho=2.5 \%$. Hence, for each of the three models, this leaves us with four parameters to be estimated: $\sigma_{a}, \sigma_{i}, K, F$.

\subsection{Moments used in the estimation}

We use monthly time series of price-setting statistics from January 1998 to January 2005, constructed by Klenow and Kryvtsov (2008). ${ }^{19}$ Those statistics were computed from individual price changes (excluding sales) in the micro data underlying the US Bureau of Labor Stastics CPI for the top urban areas of the United States. The sample period dictates the calibration of the average inflation rate $(\mu=3.3 \%$ per year).

\footnotetext{
${ }^{16}$ We simulate economies with 10,000 firms, which is in the ballpark o fthe number of quote lines $(13,000-140,000)$ underlying the price-setting statistics that we use in the estimation (see Klenow and Kryvtsov 2008).

${ }^{17}$ We compute the artificial moments $\Psi_{\text {sim }}(\Phi)$ based on 20 artificial samples of the same time span as the actual data. Hence, the variance-covariance matrix underlying $W$ equals 1.05 times the variance-covariance matrix of the sample moments in the data (see, e.g., DeJong and Dave 2007, page 161).

${ }^{18}$ This is only strictly true in the limit with an infinite number of firms. In simulations with a finite number of firms, idiosyncratic shocks do produce variation in aggregate price-setting statistics. Hence the importance of simulating the model with a number of firms that is comparable to the number of quote lines in the micro data from which the empirical moments are obtained (see footnote 16).

${ }^{19}$ We thank Oleksiy Kryvtsov for sharing the time series with us.
} 
The price-setting statistics used in the estimation are: i) frequency of positive price changes; ii) frequency of negative price changes; iii) mean size of price changes; iv) median size of price changes; and v) the frequency of positive price changes squared. We now provide some intuition for why matching these moments identifies our parameters of interest. ${ }^{20}$

The adjustment cost parameter $K$ clearly affects the frequency of both positive and negative price changes. With a positive drift in the frictionless optimal price process $(\mu>0)$, positive adjustments are more frequent than negative adjustments. However, because the distributions of shocks are symmetric, the higher the variance of idiosyncratic shocks is, the smaller that asymmetry between positive and negative price adjustments becomes. Fully informed price adjustments tend to be larger and more variable than partially informed (or uninformed) adjustments. ${ }^{21}$ Thus, a decrease in information costs $(F)$ tends to increase the mean and the variance of adjustment sizes, affecting both the mean and the median of the size distribution. Finally, the incidence of aggregate shocks can produce meaningful time variation in the frequency of price changes - both positive and negative. Hence our use of the frequency of positive price changes squared as an estimation target.

\subsection{Results}

Tables 1 and 2 present our estimation results. Table 1 reports estimates of the model parameters, whereas Table 2 compares data moments with those produced by the different estimated models. All three models fit the targeted moments comparably well. But there are important differences in the estimated parameters. The model with partial information in which aggregate information is free and the model with costly information only produce relatively similar estimates. In contrast, the model with costly aggregate information leads to higher estimates for the variance of aggregate shocks and lower estimates of idiosyncratic shocks, coupled with significantly higher information and adjustment costs (approximately 3 times higher).

Figure 4 shows the optimal price-setting rules corresponding to the three estimated models. Notice that the model with partial information in which aggregate information is free and the model with costly information only produce quite similar pricing policies. In contrast, the model with costly aggregate information leads to a very different optimal policy, despite the fact that it fits the same data moments. The latter model features an inaction region that essentially encompasses the ones produced by the other two estimated models. The bands that define its adjustment

\footnotetext{
${ }^{20}$ We used Monte Carlo simulations to confirm that our SMM estimation with these moments recovers the parameters of the model used to generate the artificial samples.

${ }^{21}$ The size of partially informed (or uninformed) adjustments is pinned down by the distance between the adjustment barriers $(l(\tau), u(\tau))$ and the target point $c(\tau)$. These distances do not vary that much with $\tau$ (see, e.g., Figure $1)$. In contrast, fully informed price increase (decreses) have minimum size given by $c(0)-l(0)(u(0)-c(0))$, but no upper bound.
} 


\begin{tabular}{lcccc}
\hline \hline \multicolumn{5}{c}{ Estimated Parameters } \\
\hline \hline & $\boldsymbol{\sigma}_{a}$ & $\sigma_{i}$ & $F$ & $K$ \\
\hline \hline No Partial Info & $\mathbf{0 . 0 2 5 4}$ & $\mathbf{0 . 1 9 0 5}$ & $\mathbf{0 . 0 0 0 6 5}$ & $\mathbf{0 . 0 0 0 2 4}$ \\
standard deviation & 0.0013 & 0.0025 & $1.36 \mathrm{e}-05$ & $1.03 \mathrm{e}-05$ \\
t-statistic & 19.9 & 74.8 & 48.0 & 23.1 \\
Partial Info $\left(\sigma_{a}=\sigma_{f}\right)$ & $\mathbf{0 . 0 1 8 1}$ & $\mathbf{0 . 1 9 1 1}$ & $\mathbf{0 . 0 0 0 7 1}$ & $\mathbf{0 . 0 0 0 2 5}$ \\
standard deviation & 0.0018 & 0.0033 & $1.72 \mathrm{e}-05$ & $6.27 \mathrm{e}-06$ \\
t-statistic & 10.1 & 57.5 & 41.2 & 39.6 \\
Partial Info $\left(\sigma_{a}=\sigma_{c}\right)$ & $\mathbf{0 . 0 9 9 9}$ & $\mathbf{0 . 1 4 5 9}$ & $\mathbf{0 . 0 0 2 1 1}$ & $\mathbf{0 . 0 0 0 7 6}$ \\
standard deviation & 0.0004 & 0.0066 & 0.0002 & 0.0002 \\
t-statistic & 216.3 & 22.0 & 11.6 & 4.5 \\
\hline \hline
\end{tabular}

Table 1: Estimation Results - parameters

\begin{tabular}{cccccc}
\hline \hline \multicolumn{5}{c}{ Target Statistics } \\
\hline \hline Statistic & freq $\Delta p>0$ & freq $\Delta p<0$ & mean $|\Delta p|$ & median $|\Delta p|$ & $(\text { fr } \Delta p>0)^{2}$ \\
Data & 0.1503 & 0.1152 & 0.0900 & 0.0710 & 0.0233 \\
No Partial Info & 0.1465 & 0.1252 & 0.0953 & 0.0842 & 0.0221 \\
Partial $\sigma_{a}=\sigma_{f}$ & 0.1477 & 0.1247 & 0.0949 & 0.0838 & 0.0231 \\
Partial $\sigma_{a}=\sigma_{c}$ & 0.1505 & 0.1227 & 0.0915 & 0.0788 & 0.0236 \\
\hline \hline
\end{tabular}

Table 2: Simulated statistics with estimated parameters compared to real data

inaction region are wider than in the the other two models, and information collection happens much less frequently. These differences are reflected in different price-setting statistics, reportet in Table 3. Information collection occurs much more often $(\approx 4.7$ times a year vs. 1.4$)$ in the models with costly information only and free aggregate information. Another striking difference is that in those two models almost all adjustments are fully informed. In sharp contrast, $75 \%$ of price adjustments in the model with costly aggregate information are based only on information about idiosyncratic shocks. In all models, when costly information is collected, price adjustments happen with a similar frequency - between $65-70 \%$ of the time.

The intuion for these results is clear. The estimated model with costly idiosyncratic information features small aggregate shocks. As a result, they rarely lead to partially informed adjustments. Hence, this partial information model produces results that are similar to those in which the (small) aggregate shocks are also costly to observe, as in the model with costly information only. Things are different in the model with costly aggregate information. Since the flow profit loss is a convex function of the price discrepancy, the fact that the firm can react to news about its volatile idiosyncratic component reduces the incentives to gather costly information frequently. Hence, for a given information gathering cost $F$, the firm would choose to sample less frequently. In addition, the estimated information cost in the model with costly aggregate information is (approximately 3 


\begin{tabular}{||l|l|l||l||}
\hline \hline Baseline & No Partial Info & Partial Info & Partial Info \\
\hline & & $\left(\sigma_{a}=\sigma_{f}\right)$ & $\left(\sigma_{a}=\sigma_{c}\right)$ \\
\hline$K$ & 0.00024 & 0.00025 & 0.00076 \\
\hline$F$ & 0.00065 & 0.00071 & 0.00211 \\
\hline Adjustments per year & 3.36 & 3.26 & 3.59 \\
\hline fully info. adj & $100 \%$ & $98 \%$ & $25 \%$ \\
\hline adj. without (full) info & $0 \%$ & $2 \%$ & $75 \%$ \\
\hline Information gatherings per year & 4.88 & 4.64 & 1.37 \\
\hline resulting in immediate adj. & $69 \%$ & $69 \%$ & $65 \%$ \\
\hline \hline
\end{tabular}

Table 3: Implied statistics for estimated rules

times) higher than in the other two models, also contributing to less frequent information gathering.

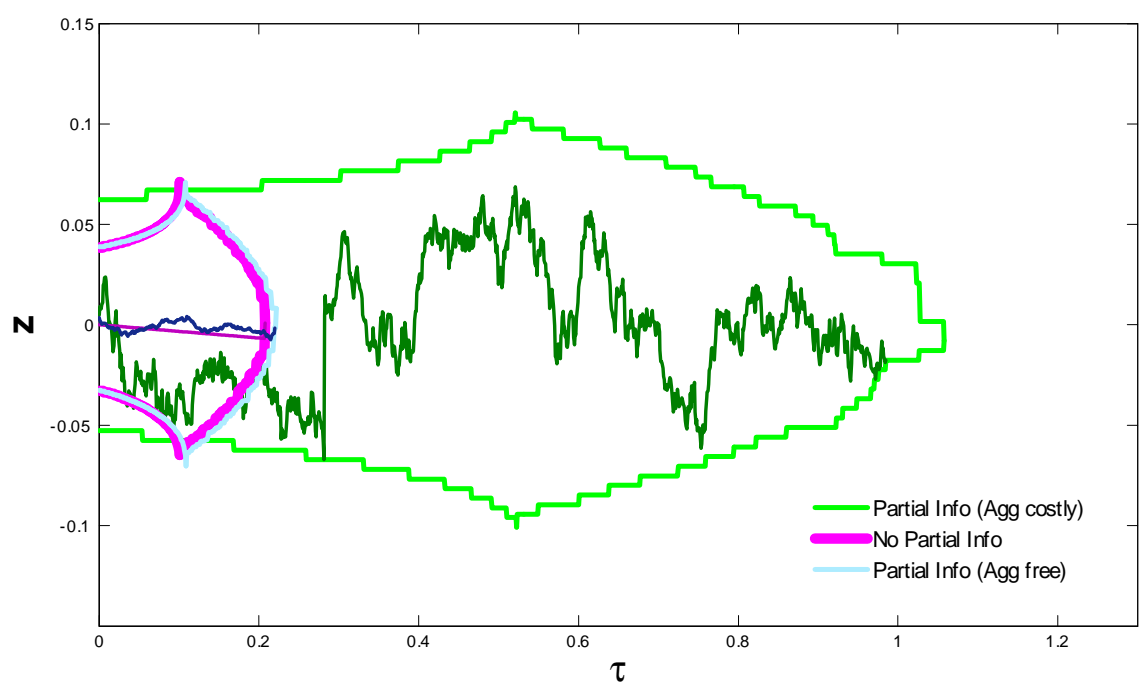

Figure 3: Estimated Costly Only Information and Partial Information Rule with Costly Aggregate Information

While all three estimated models fit targeted moments equally well, they do have sharply different implications for an untargeted moment: the distribution of the duration of price spells. In particular, the models with costly information only and with free aggregate information produce counterfactual distributions, with "gaps" that do not appear in the empirical distribution reported by Klenow and Kryvtsov (2008). In contrast, the model with costly aggregate information leads to a distribution that resembles that empirical distribution (see figures below). 


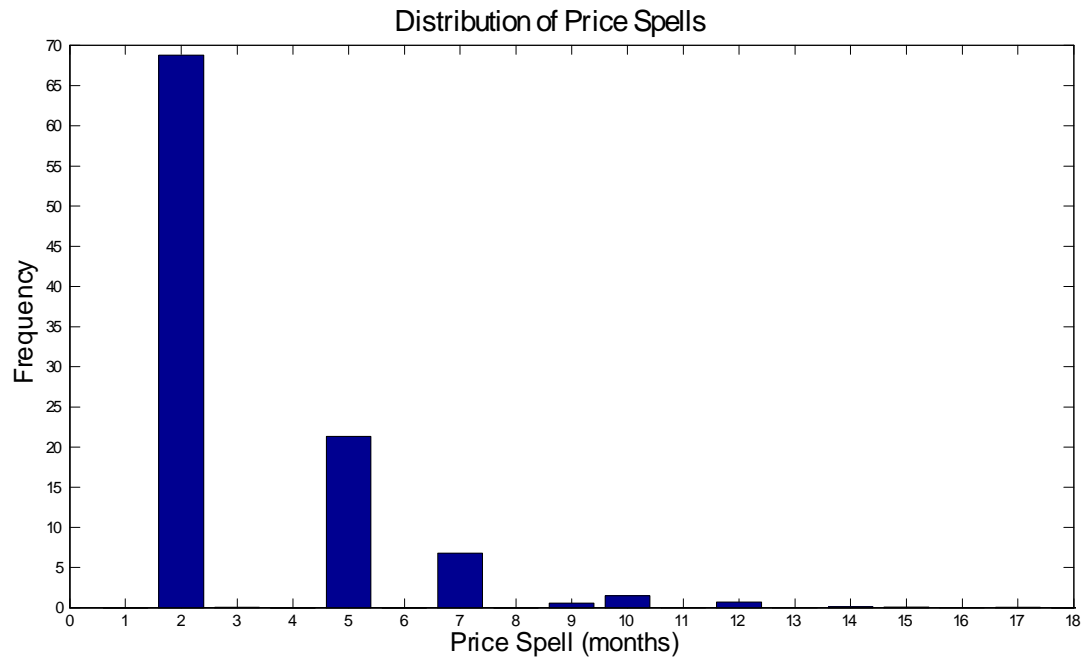

Figure 4: No Partial Information

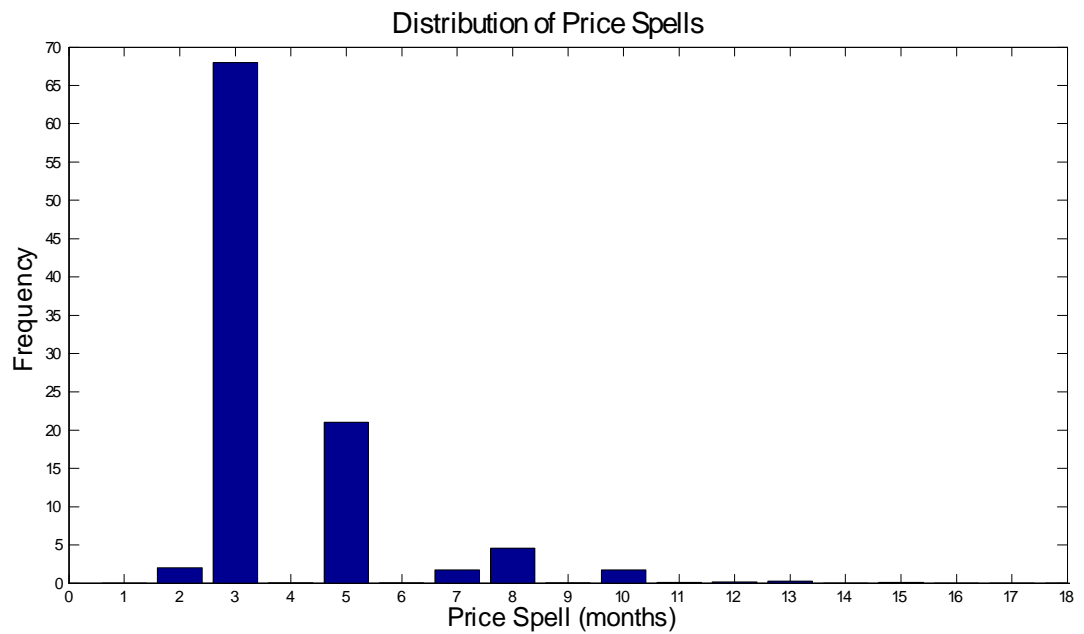

Figure 5: Partial Information Model with Free Aggregate Information 


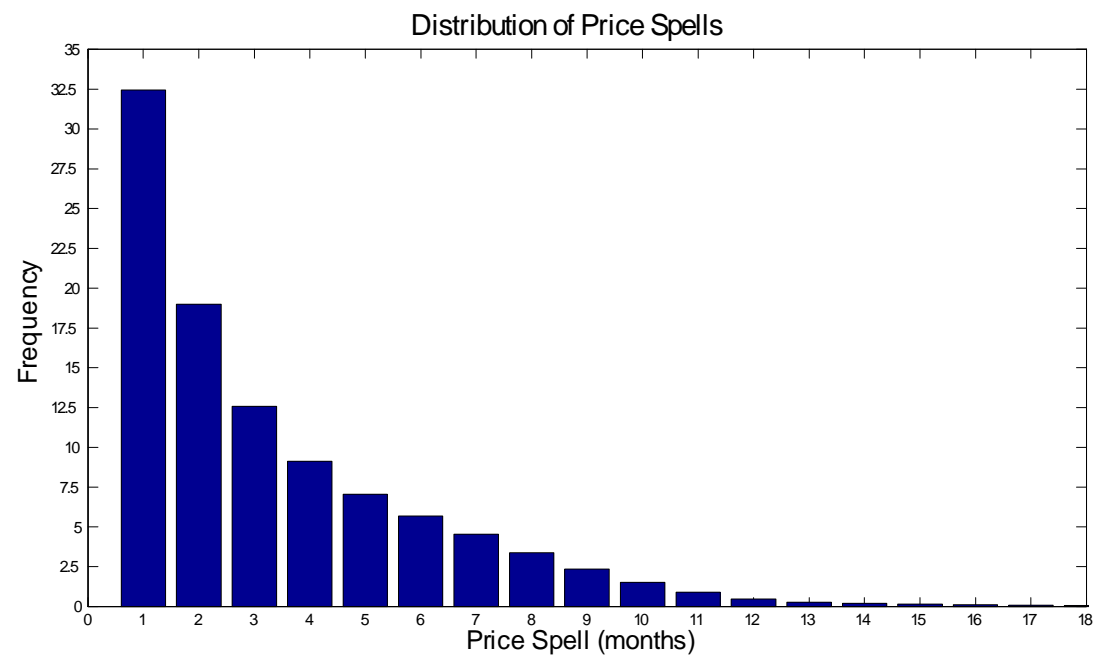

Figure 6: Partial Information Model with Free Idiosyncratic Information

\section{Macroeconomic Effects}

In the model above (see also Appendix A) the logarithm of the frictionless price equal to the sum of the logarithm of the nominal aggregate demand and the idiosyncractic productivity shock. We assumed that nominal aggregate demand $\mathcal{M}_{t}$ follows a geometric Brownian motion with trend growth $\mu$. An unanticipated shock to the level of nominal aggregate demand makes it jump in time zero from $\mathcal{M}_{0}$ to $\mathcal{M}_{0}(1+\zeta)$. After the jump, the nominal aggregate demand resumes its trend.

For the best estimated partial information model and for the model with costly information only, we simulate a large number of firms for time long enough to reach the stochastic steady. Then, we give the shock to nominal aggregate demand and continue the simulation with nominal aggregate demand evolving as before. We aggregate individual prices to obtain the average price level. The output (in logs) is given by:

$$
y_{t}=\log \mathcal{M}_{t}-p_{t}
$$

The result is showed in Figure 10. Despite the fact that both models display similar frequency of price adjustments, they display very different macroeconomic dynamics. For both models, output immediately increases and falls back to the original level, but at different rates. Output is back at the original level after a little more than two months, for the model with costly only information, while it takes almost a year to falls back in the partial information model. The reason is clear: while in the costly information only aggregate information is collected at time intervals ranging between 1.8 to 2.5 months, in the partial information model aggregate information is gathered 7.5 
to 14.5 months after the last information time.

Notice that those results are obtained in a model with no strategic complementarities in price. Therefore, the high persistence of the money effect obtained in the partial information model contributes to reconcile the micro evidence of relatively frequent price adjustments with the macro evidence of persistent effects of monetary policy.

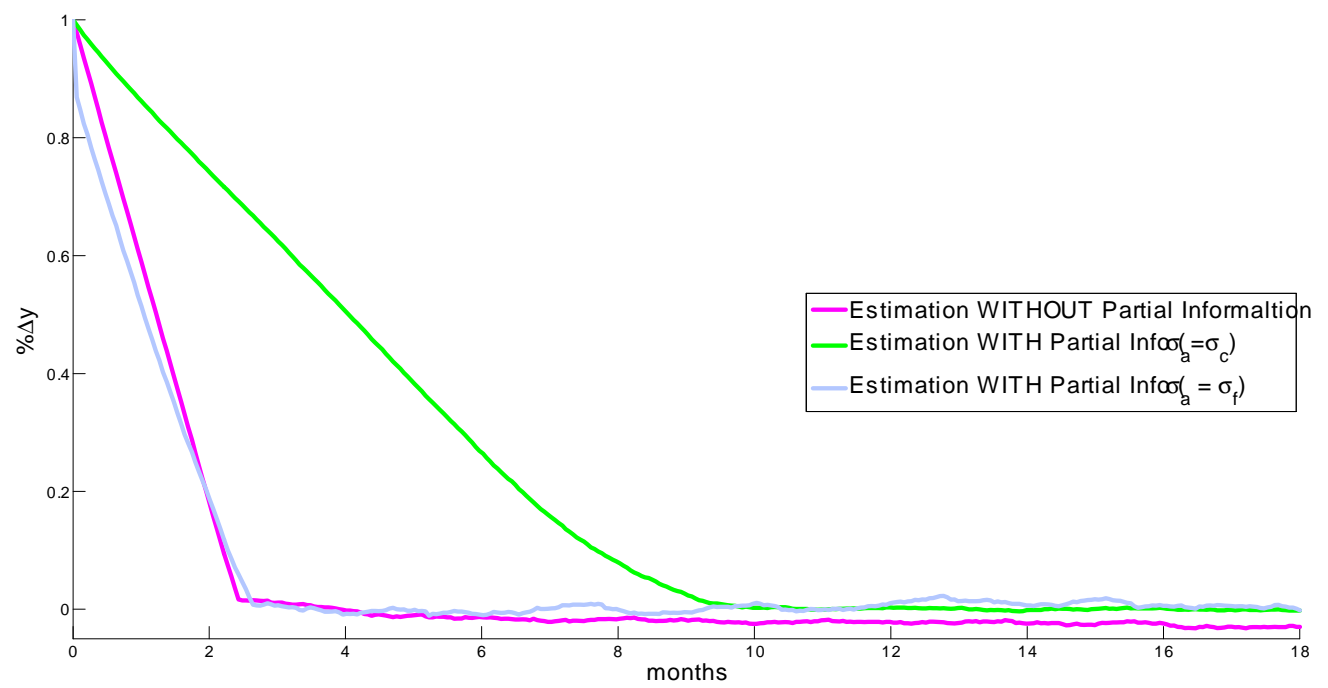

In Panel 1 we show how changing $K$ and $F$ affects the persistence of the money shock effect in both partial information and costly information only models. It is striking that a change in the information cost has a much stronger effect than changing adjustment costs, and more so in the partial information model. As emphasized in the literature, information costs are key to explaining macroeconomic effects. An apparently paradoxical result is that in the partial information model an increase in the adjustment cost reduces the persistence of the money shock effect. The analysis above sheds light in this result. Although the frequency of adjustments decreases, information collection increases. As a result there are more frequent adjustments with updated information about the aggregate shock.

\section{Conclusion}

We propose a price-setting model which helps to reconcile micro evidence of relatively frequent price adjustments with macroeconomic persistent effects of aggregate shocks. In our model both adjustments and the gathering of some type of information are costly, requiring the payment of some lump-sum. Additionally, another relevant part of the information flows continuously and can be factored into pricing decisions costlessly. When we assume that this free information is 

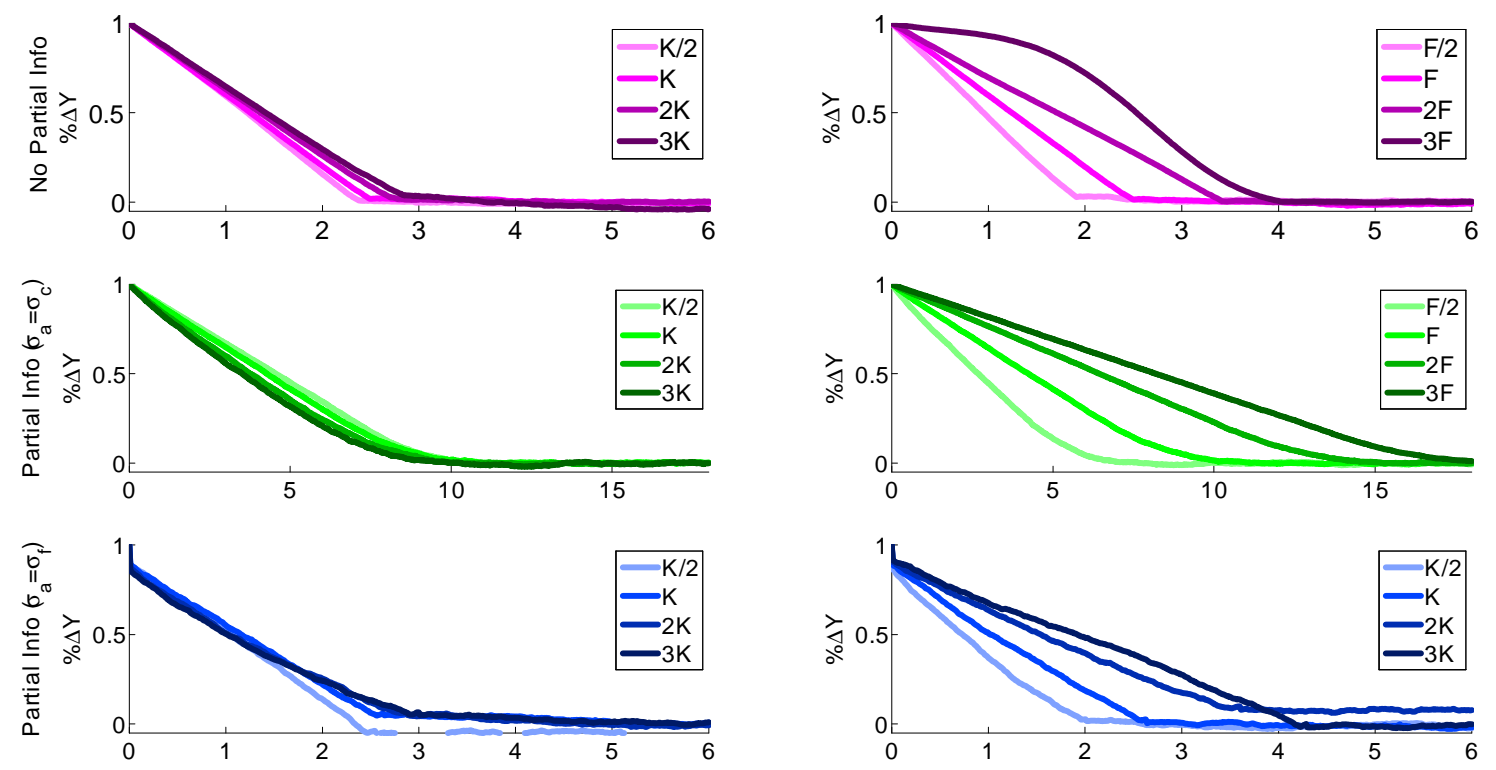

idiosyncratic and the costly information is aggregate, our model is able to match the individual US price-setting statistics and, at the same time, to produce persistent macroeconomic effects. The assumption of free information about idiosyncratic shocks leads to low frequency of aggregate information collection, which turns out to be crucial for the persistence effects of aggregate shocks. 


\section{References}

[1] Abel, A., J. Eberly and S. Panageas (2009), "Optimal Inattention to the Stock Market with Information Costs and Transactions Costs," NBER Working Paper \#15010.

[2] Almeida, H. and M. Bonomo (2002), "Optimal State-Dependent Rules, Credibility and Inflation Inertia," Journal of Monetary Economics 49: 1317-1336.

[3] Alvarez, F., L. Guiso, and F. Lippi (2010), "Durable Consumption and Asset Management with Transaction and Observation Costs," NBER Working Paper \#15835.

[4] Alvarez, F., F. Lippi, and L. Paciello (2010), "Optimal Price Setting with Observation and Menu Costs," NBER Working Paper \#15852.

[5] Ball, L., G. Mankiw and D. Romer (1988), "The New Keynesian Economics and the OutputInflation Trade-off," Brookings Papers on Economic Activity 1: 1-65.

[6] Ball, L. and D. Romer (1990), "Real Rigidities and the Non-Neutrality of Money," Review of Economic Studies 57: 183-203.

[7] Bils, M. and P. Klenow (2004), "Some Evidence on the Importance of Sticky Prices," Journal of Political Economy 112: 947-985.

[8] Bonomo, M. and C. Carvalho (2004), "Endogenous Time-Dependent Rules and Inflation Inertia," Journal of Money, Credit and Banking 36: 1015-1041.

[9] (2010), "Imperfectly-Credible Disinflation under Endogenous Time-Dependent Pricing," Journal of Money, Credit and Banking 42: 799-831.

[10] Bonomo, M., C. Carvalho, and R. Garcia (2011), "State-dependent Pricing under Infrequent Information: A Unified Framework," Federal Reserve Bank of New York Staff Reports \#455.

[11] Bonomo, M. and R. Garcia (1994), "Indexation, Staggering and Disinflation," Journal of Development Economics 43: 39-58.

[12] (2001), "The Macroeconomic Effects of Infrequent Information with Adjustment Costs," Canadian Journal of Economics 34: 18-35.

$[13]$ (2003), "Optimal Rules under Adjustment Cost and Infrequent Information," mimeo available at http://repec.org/esLATM04/up.7597.1081885890.pdf. 
[14] Burstein, A. (2006), "Inflation and Output Dynamics with State-Dependent Pricing Decisions," Journal of Monetary Economics 53: 1235-1257.

[15] Caballero, R. (1989), "Time Dependent Rules, Aggregate Stickiness and Information Externalities," Working Paper no. 428, Columbia University.

[16] Calvo, G. (1983), "Staggered Prices in a Utility Maximizing Framework," Journal of Monetary Economics 12: 383-98.

[17] Caplin, A. and J. Leahy (1991), "State-Dependent Pricing and the Dynamics of Money and Output," Quarterly Journal of Economics 106: 683-708.

[18] _ (1997), "Aggregation and Optimization with State-Dependent Pricing," Econometrica 65: 601-625.

[19] Caplin, A. and D. Spulber (1987), "Menu Costs and the Neutrality of Money," Quarterly Journal of Economics 102: 703-726.

[20] Danziger, L. (1999), “A Dynamic Economy with Costly Price Adjustments," American Economic Review 89: 878-901.

[21] Dhyne, E., L. Álvarez, H. Le Bihan, G. Veronese, D. Dias, J. Hoffman, N. Jonker, P. Lünnemann, F. Rumler and J. Vilmunen (2006), "Price Changes in the Euro Area and the United States: Some Facts from Individual Consumer Price Data," Journal of Economic Perspectives 20: $171-192$.

[22] Dias, D., C. Marques and J. Silva (2007), "Time- or state-dependent price setting rules? Evidence from micro data," European Economic Review 51: 1589-1613.

[23] Gertler, M. and J. Leahy (2008), "A Phillips Curve with an Ss Foundation," Journal of Political Economy 116: 533-572.

[24] Golosov, M. and R. Lucas (2007), "Menu Costs and Phillips Curves," Journal of Political Economy 115: 171-199.

[25] Gorodnichenko, Y. (2008), "Endogenous Information, Menu Costs and Inflation Persistence," NBER Working Paper No. 14184.

[26] Jadresic, E. (2002), "The Macroeconomic Consequences of Wage Indexation Revisited," in F. Lefort, and K. Schmidt-Hebbel (orgs.), Indexation, Inflation and Monetary Policy, Central Bank of Chile. 
[27] Klenow, P., and O. Kryvtsov (2008), "State-Dependent or Time-Dependent Pricing: Does It Matter for Recent U.S. Inflation?" Quarterly Journal of Economics 123: 863-904

[28] Klenow, P. and J. Willis (2007), "Sticky Information and Sticky Prices," Journal of Monetary Economics 54: 79-99.

[29] Knotek, E. (2010), "A Tale of Two Rigidities: Sticky Prices in a Sticky-Information Environment," Journal of Money, Credit, and Banking 42: 1543-64.

[30] Kongsamut, P., S. Rebelo and D. Xie (2001), "Beyond Balanced Growth," Review of Economic Studies 68: 869-882.

[31] Kryvtsov, O. (2009), "Information Flows and Aggregate Persistence," mimeo available at http://www.kryvtsov.com.

[32] Maćkowiak, B., and M. Wiederholt (2008), "Optimal Sticky Prices under Rational Inattention," American Economic Review 99: 769-803.

[33] Mankiw, G., and R. Reis (2002), "Sticky Information Versus Sticky Prices: A Proposal to Replace the New Keynesian Phillips Curve," Quarterly Journal of Economics 117: 1295-1328.

[34] Midrigan, V. (2010), "Is Firm Pricing State or Time-Dependent? Evidence from US Manufacturing," Review of Economics and Statistics 92: 643-656.

[35] _ (2011), "Menu Costs, Multi-Product Firms and Aggregate Fluctuations," Econometrica 79: 1139-1180.

[36] Moscarini, G. (2004), "Limited Information Capacity as a Source of Inertia," Journal of Economic Dynamics and Control 28: 2003-2035.

[37] Nakamura, E. and J. Steinsson (2010), "Monetary Non-Neutrality in a Multi-Sector Menu Cost Model," Quarterly Journal of Economics 125: 961-1013.

[38] Phelps, E. (1978), "Disinflation without Recession: Adaptive Cuideposts and Monetary Policy," Weltwirtschaftliches Archiv 114: 783-809.

[39] Reis, R. (2006), "Inattentive Producers," Review of Economic Studies 73: 793-821.

[40] Sheshinski, E. and Y. Weiss (1977), "Inflation and Costs of Price Adjustment," Review of Economic Studies 44: 287-304. 
[41] Taylor, J. (1979), "Staggered Price Setting in a Macro Model," Journal of Political Economy 88: 1-24.

[42] Taylor, J. (1980), "Aggregate Dynamics and Staggered Contracts," Journal of Political Economy 88: 1-23.

[43] Woodford, M. (2003), Interest and Prices: Foundations of a Theory of Monetary Policy, Princeton University Press.

[44] (2009), "Information-Constrained State-Dependent Pricing," Journal of Monetary Economics 56, Supplement: S100-S124.

[45] Yun, T. (1996), "Nominal Price Rigidity, Money Supply Endogeneity, and Business Cycles," Journal of Monetary Economics 37: 345 - 370. 


\section{Appendix A}

We derive the frictionless optimal price in a simple general equilibrium framework. A representative consumer maximizes expected discounted utility:

$$
E_{t_{0}} \int_{t_{0}}^{\infty} e^{-\rho\left(t-t_{0}\right)}\left[\log \left(C_{t}\right)-H_{t}\right] d t
$$

subject to the budget constraints:

$$
B_{t}=B_{0}+\int_{0}^{t} W_{r} H_{r} d r-\int_{0}^{t}\left(\int_{0}^{1} P_{i r} C_{i r} d i\right) d r+\int_{0}^{t} T_{r} d r+\int_{0}^{t} \Lambda_{r} d Q_{r}+\int_{0}^{t} \Lambda_{r} d D_{r}, \text { for } t \geq 0 .
$$

Utility is defined over the composite consumption good $C_{t} \equiv\left[\int_{0}^{1}\left(C_{i t} / A_{i t}\right)^{\frac{\theta-1}{\theta}} d i\right]^{\frac{\theta}{\theta-1}}$ with $\theta>1$, where $C_{i t}$ is the consumption of variety $i$, and $A_{i t}$ is a relative-preference shock. $P_{i t}$ is the price of variety $i, H_{t}$ is the supply of labor, which commands a wage $W_{t}, B_{t}$ is total financial wealth, $T_{t}$ are total net transfers, including any lump-sum flow transfer from the government, and profits received from the firms owned by the representative consumer. $Q_{r}$ is the vector of prices of traded assets, $D_{r}$ is the corresponding vector of cumulative dividend processes, and $\Lambda_{r}$ is the trading strategy, which satisfies conditions that preclude Ponzi schemes. The associated consumption price index, $P_{t}$, is given by:

$$
P_{t}=\left[\int_{0}^{1} P_{i t}^{1-\theta} d i\right]^{\frac{1}{1-\theta}}
$$

The demand for an individual variety is:

$$
C_{i t}=A_{i t}^{1-\theta}\left(\frac{P_{i t}}{P_{t}}\right)^{-\theta} C_{t}
$$

Firms hire labor to produce according to the following production function:

$$
Y_{i t}=A_{i t} H_{i t}
$$

Note that we assume that the productivity shock is perfectly correlated with the relative-preference shock in the consumption aggregator. This has precedence in the sticky-price literature (for instance, King and Wolman 1999 and Woodford 2009). Our specific assumption follows Woodford (2009), and aims to produce a tractable profit-maximization problem that can be written as a price-setting "tracking problem" in which the firm only cares about the ratio of the two stochastic processes driving profits, which will be specified below. ${ }^{22}$

\footnotetext{
${ }^{22}$ More generally, assumptions relating preference and technology processes have been used previously in the literature on "balanced growth" in multi-sector models (e.g. Kongsamut et al. 2001).
} 
The static profit-maximizing price for firm $i, P_{i t}^{*}$ (also referred to as its frictionless optimal price), is given by the usual markup rule:

$$
P_{i t}^{*}=\frac{\theta}{\theta-1} \frac{W_{t}}{A_{i t}}
$$

From the representative household's labor supply:

$$
\frac{W_{t}}{P_{t}}=C_{t}
$$

which leads to:

$$
P_{i t}^{*}=\frac{\theta}{\theta-1} \frac{P_{t} C_{t}}{A_{i t}} .
$$

In logarithms (lowercase variables denote logarithms throughout), this reads:

$$
p_{i t}^{*}=\log \left(\frac{\theta}{\theta-1}\right)+\log \left(P_{t} C_{t}\right)-\log \left(A_{i t}\right) .
$$

Ignoring the unimportant constant and assuming appropriate exogenous stochastic processes for nominal aggregate demand and for idiosyncratic productivity yields the specifications used throughout the main text.

\section{Appendix B}

Here we derive the quadratic approximation to the static profit-maximization problem used in the main text. Write real flow profits as:

$$
\Pi\left(\frac{P_{i}}{P}, C, A_{i}\right)=A_{i}^{1-\theta} \frac{P_{i}}{P}\left(\frac{P_{i}}{P}\right)^{-\theta} C-\frac{W}{P A_{i}} A_{i}^{1-\theta}\left(\frac{P_{i}}{P}\right)^{-\theta} C,
$$

where $P_{i}$ is the price charged by firm $i$. We can use the labor supply equation to express the real wage as a function of aggregate consumption $\left(\frac{W}{P}=C\right)$, and rewrite the expression for real flow profits as:

$$
\Pi\left(\frac{P_{i}}{P}, C, A_{i}\right)=A_{i}^{1-\theta}\left(\frac{P_{i}}{P}\right)^{1-\theta} C-C^{2} A_{i}^{-\theta}\left(\frac{P_{i}}{P}\right)^{-\theta} .
$$

Let $\bar{\Pi}$ be the steady-state level of real profits in a frictionless economy (upper bars denote steady-state values): ${ }^{23}$

$$
\bar{\Pi} \equiv \Pi\left(\frac{P_{i}^{*}}{P}, \bar{C}, A_{i}\right)
$$

\footnotetext{
${ }^{23} \mathrm{~A}$ constant level of aggregate consumption requires the restriction $\left[\int_{0}^{1} A_{i t}^{\theta-1} d i\right]^{\frac{1}{1-\theta}}=1$, which we assume holds throughout the paper.
} 
We want to approximate the loss function $\overline{\bar{L}}$ defined as:

$$
\begin{aligned}
\overline{\bar{L}}\left(\frac{P_{i}^{*}}{P}, \frac{P_{i}}{P}, C, A_{i}\right) & =\frac{\Pi\left(\frac{P_{i}^{*}}{P}, C, A_{i}\right)-\Pi\left(\frac{P_{i}}{P}, C, A_{i}\right)}{\bar{\Pi}} \\
& =\frac{\Pi\left(\frac{P_{i}^{*}}{P}, C, A_{i}\right)-\Pi\left(\frac{P_{i}}{P}, C, A_{i}\right)}{\Pi\left(\frac{P_{i}^{*}}{P}, C, A_{i}\right)} \frac{\left.P_{i}^{*}, \bar{C}, A_{i}\right)}{\bar{\Pi}},
\end{aligned}
$$

The second ratio in (16) can be written as:

$$
\begin{aligned}
\frac{\Pi\left(\frac{P_{i}^{*}}{P}, C, A_{i}\right)}{\bar{\Pi}} & =\frac{A_{i}^{1-\theta}\left(\frac{P_{i}^{*}}{P}\right)^{1-\theta} C-C^{2} A_{i}^{-\theta}\left(\frac{P_{i}^{*}}{P}\right)^{-\theta}}{\bar{C}-\bar{C}^{2}} \\
& =\frac{A_{i}^{1-\theta}\left(\frac{P_{i}^{*}}{P}\right)^{1-\theta} C-\frac{\theta-1}{\theta} C A_{i}^{1-\theta}\left(\frac{P_{i}^{*}}{P}\right)^{1-\theta}}{\bar{C}-\frac{\theta-1}{\theta} \bar{C}} \\
& =A_{i}^{1-\theta} \frac{C}{\bar{C}}\left(\frac{P_{i}^{*}}{P}\right)^{1-\theta} \\
& =\left(\frac{C}{\bar{C}}\right)^{2-\theta},
\end{aligned}
$$

where we use the facts that $\frac{P_{i}^{*}}{P}=\frac{\theta}{\theta-1} \frac{C}{A_{i}}$ and $\bar{C}=\frac{\theta-1}{\theta}$. Note how the link between preferences and technology makes the idiosyncratic shock drop from the expression for maximized profits.

The first ratio in (16) is the proportional profit loss due to the "suboptimal" price $P_{i}$. It is convenient to rewrite it as:

$$
\frac{\Pi\left(\frac{P_{i}^{*}}{P}, C, A_{i}\right)-\Pi\left(\frac{P_{i}}{P}, C, A_{i}\right)}{\Pi\left(\frac{P_{i}^{*}}{P}, C, A_{i}\right)}=1-\frac{\Pi\left(\frac{P_{i}}{P}, C, A_{i}\right)}{\Pi\left(\frac{P_{i}^{*}}{P}, C, A_{i}\right)} .
$$

The profit ratio in the above expression can be written as:

$$
\begin{aligned}
\frac{\Pi\left(\frac{P_{i}}{P}, C, A_{i}\right)}{\Pi\left(\frac{P_{i}^{*}}{P}, C, A_{i}\right)} & =\frac{A_{i}^{1-\theta}\left(\frac{P_{i}}{P}\right)^{1-\theta} C-C^{2} A_{i}^{-\theta}\left(\frac{P_{i}}{P}\right)^{-\theta}}{A_{i}^{1-\theta}\left(\frac{P_{i}^{*}}{P}\right)^{1-\theta} C-C^{2} A_{i}^{-\theta}\left(\frac{P_{i}^{*}}{P}\right)^{-\theta}} \\
& =\frac{A_{i}^{1-\theta}\left(\frac{P_{i}}{P}\right)^{1-\theta}-\frac{\theta-1}{\theta} \frac{P_{i}^{*}}{P} A_{i}^{1-\theta}\left(\frac{P_{i}}{P}\right)^{-\theta}}{A_{i}^{1-\theta}\left(\frac{P_{i}^{*}}{P}\right)^{1-\theta}-\frac{\theta-1}{\theta} \frac{P_{i}^{*}}{P} A_{i}^{1-\theta}\left(\frac{P_{i}^{*}}{P}\right)^{-\theta}} \\
& =\theta \frac{\left(\frac{P_{i}}{P}\right)^{1-\theta}-\frac{\theta-1}{\theta} \frac{P_{i}^{*}}{P}\left(\frac{P_{i}}{P}\right)^{-\theta}}{\left(\frac{P_{i}^{*}}{P}\right)^{1-\theta}} \\
& =\theta\left(\frac{P_{i}^{*}}{P_{i}}\right)^{\theta-1}-(\theta-1)\left(\frac{P_{i}^{*}}{P_{i}}\right)^{\theta},
\end{aligned}
$$


so that:

$$
\frac{\Pi\left(\frac{P_{i}^{*}}{P}, C, A_{i}\right)-\Pi\left(\frac{P_{i}}{P}, C, A_{i}\right)}{\Pi\left(\frac{P_{i}^{*}}{P}, C, A_{i}\right)}=1-\theta\left(\frac{P_{i}^{*}}{P_{i}}\right)^{\theta-1}+(\theta-1)\left(\frac{P_{i}^{*}}{P_{i}}\right)^{\theta} .
$$

As before, note how the link between preference and technology makes the idiosyncratic shock drop from the expression above.

Combining (17) and (18), and keeping the relevant arguments of the loss function, we obtain:

$$
\overline{\bar{L}}\left(\frac{P_{i}^{*}}{P}, \frac{P_{i}}{P}, C, A_{i}\right)=\bar{L}\left(\frac{P_{i}^{*}}{P_{i}}, C\right)=\left(\frac{C}{\bar{C}}\right)^{2-\theta}\left[1-\theta\left(\frac{P_{i}^{*}}{P_{i}}\right)^{\theta-1}+(\theta-1)\left(\frac{P_{i}^{*}}{P_{i}}\right)^{\theta}\right] .
$$

We can rewrite the loss function $\bar{L}$ in terms of logarithms:

$$
G\left(p_{i}^{*}-p_{i}, c\right)=e^{(2-\theta) c}\left[\left(1-\theta e^{(\theta-1)\left(p_{i}^{*}-p_{i}\right)}\right)+(\theta-1) e^{\theta\left(p_{i}^{*}-p_{i}\right)}\right] .
$$

The exact loss function $G\left(p_{i}^{*}-p_{i}, c\right)$ can be used in the optimal price-setting problems. However, the presence of aggregate consumption in the expression implies that solving for the optimal pricing rule in the presence of pricing frictions involves a fixed-point problem, even in the absence of strategic complementarity or substitutability in price setting. To make the optimal pricing problem more tractable, we eliminate the effect of aggregate output by assuming $\theta=2$ (as in Danziger 1999 and Bonomo and Carvalho 2010). In addition, for analytical convenience we take a second-order Taylor expansion of flow profit losses around the frictionless optimal price, based on which we analyze the price-setting problems discussed in the paper:

$$
\text { flow profit losses }\left(p_{i t}\right) \propto\left(p_{i t}-p_{i t}^{*}\right)^{2} \text {. }
$$




\section{Appendix $\mathrm{C}$}

The firm's problem at any information date labeled $t_{0}^{0}$ is given by the following intertemporal optimization program: ${ }^{24}$

$$
\begin{gathered}
V\left(s_{t_{0}^{0}}, p_{t_{-1} N_{-1}}\right)= \\
\left\{t_{j}^{0},\left\{t_{j}^{n}, p_{t_{j}^{n}}\right\}_{n=1}^{N_{j}}\right\}_{j=1}^{\infty} E_{t_{0}^{0}} \sum_{j=0}^{\infty} E_{t_{j}^{0}}\left\{\begin{array}{c}
e^{-\rho\left(t_{j+1}^{0}-t_{0}^{0}\right)} F+\int_{t_{j}^{0}}^{t_{j}^{1}} e^{-\rho\left(r-t_{0}^{0}\right)}\left(p_{t_{j-1}^{N_{j-1}}}-p_{r}^{*}\right)^{2} d r \\
+\sum_{n=1}^{N_{j}-1}\left[\int_{t_{j}^{n}}^{t_{j}^{n+1}} e^{-\rho\left(r-t_{0}^{0}\right)}\left(p_{t_{j}^{n}}-p_{r}^{*}\right)^{2} d r+e^{-\rho\left(t_{j}^{n}-t_{0}^{0}\right)} K\right] \\
t_{j+1}^{0} e^{-\rho\left(r-t_{0}^{0}\right)}\left(p_{t_{j}^{N_{j}}}-p_{r}^{*}\right)^{2} d r+e^{-\rho\left(t_{j}^{N_{j}}-t_{0}^{0}\right)} K
\end{array}\right\},
\end{gathered}
$$

where $s_{t_{0}^{0}}$ is the initial state, $p_{t_{-1} N_{-1}}$ the inherited price, $\rho$ is the time discount rate, and $E_{t}$ denotes the expectation operator conditional on time $t$ information.

\footnotetext{
${ }^{24}$ The formalization of the problem starting at an arbitrary date is similar, but heavier on notation.
} 